\title{
Wilson: uma análise do personagem coadjuvante no filme Náufrago
}

\author{
Nathalia Alencar Antunes ${ }^{1}$ \\ Maíra Carvalho
}

\section{Resumo}

Os personagens são o principal meio de identificação do público com o filme. Para se ter um bom personagem, é necessário pensar na construção dele. Essa construção abrange diversos aspectos: seu contexto, essência, paradoxos, características físicas entre outros. Este artigo tem como objetivo principal fazer uma análise a respeito da construção do personagem coadjuvante Wilson, no filme Náufrago (2000) de Robert Zemeckis. Wilson é uma bola de vôlei, um objeto completamente inanimado, que se apropria de vários aspectos da construção de um personagem secundário não humano. A bola de vôlei ainda possui outra ponta de análise, abordada no trabalho de maneira secundaria: a publicidade evolvida nela. O product placement, técnica de inserção estratégica das marcas em filmes, músicas e programas de televisão, apresenta-se - de uma maneira não tradicional - em Náufrago (2000), mais precisamente, nas marcas Federal Express (FedEX) e Wilson e, nesse último, traz um modelo diferenciado de propaganda.

Palavras-chave: Cinema. Personagem. Coadjuvante. Product Placement.

\footnotetext{
${ }^{1}$ Formou-se em Comunicação Social - Publicidade e Propaganda pelo UniCEUB em 2009. Trabalhou na área, estagiando na Agência de Comunicação do UniCEUB - ACC, no período entre julho/2008 a julho/2009. Participou do grupo de experimentação em cinema, CineSemFreqüência, entre 2006 e 2008. Participou do Workshop de interpretação para a Televisão com o diretor Edson Erdmann, integrando a Equipe Técnica.

${ }^{2}$ Historiadora formada pela Universidade de Brasília em 2002. Entre 2002 e 2004, pós-graduou-se em História e Estética do Cinema na Universidade de Valladolid, na Espanha. Atualmente complementa seus estudos com uma Especialização em História da Arte. Em fevereiro de 2006, foi contratada para lecionar as disciplinas de Redação e Produção Audiovisual no curso de Comunicação do Centro Universitário UNICEUB. Em 2009, foi contratada para dar aulas no IESB de Cenografia e Figurino no curso de Cinema e Mídias digitais. Desde 2001, participa de produções teatrais, publicitárias e cinemotográficas como Produtora, Diretora de Arte, Figurinista e Cenógrafa. Já participou de mais de 20 produções cinematográficas, dezenas de produções publicitárias e produziu espetáculos teatrais de repercussão nacional.
} 


\section{Introdução}

Desde sua criação, o cinema é responsável por apresentar ideias e palavras de um roteiro em realidade visual. A trajetória do cinema é repleta de personagens que marcaram a memória dos espectadores. Esses personagens, humanos ou não, são o elo do filme com o público, uma vez que o espectador vai sentir o que ele sente e viver, por meio dele, aquela história durante a sessão.

O personagem mais valorizado dentro de um filme é o protagonista, pois os acontecimentos giram em torno dele. Além do protagonista, o filme pode possuir personagens secundários que, no decorrer da história ou devido ao trabalho do ator, vão se valorizando, ganhando destaque e conquistando a atenção do público. Isso pode acontecer em qualquer gênero cinematográfico.

Um exemplo pode ser visto no filme Náufrago (2000), dirigido por Robert Zemeckis. Nesse filme, o protagonista é Chuck Noland, personagem interpretado por Tom Hanks, mas o personagem secundário, Wilson, é também parte importante da história. Wilson não é interpretado por nenhum ator, mas representado por um objeto: uma bola de vôlei. É interessante ver que a bola não é um objeto de cena, mas um personagem que ganhou a afeição do protagonista e a simpatia do público. Esse personagem não possui nenhuma fala, não é animado por nenhum tipo de efeito computadorizado e mesmo assim é relevante na história.

O trabalho tem como objetivo principal analisar como Wilson se tornou um coadjuvante no filme Náufrago (2000) e as características de construção de personagem, bem como sua interação com o protagonista e o enredo. Em um foco secundário, há uma breve análise do enredo e ainda a questão do product placement - a marca Wilson usada como personagem de um filme e a inserção da empresa Federal Express (FedEX) no enredo.

O trabalho baseou-se em pesquisa bibliográfica sobre cinema, personagens e roteiro. A bibliografia sobre cinema e roteiro foi usada para contextualizar o tema. De forma mais aprofundada, utilizou-se a bibliografia referente a personagem, de modo que explorasse a criação dos personagens secundários e os relacionamentos entre eles. Na intenção de abordar a publicidade envolvida no filme em questão, usou-se uma bibliografia complementar referente a product placement, sua definição e uso cada vez mais frequente nas telas de cinema. 


\section{Náufrago}

\subsection{A sinopse e a produção}

Náufrago (2000), de Robert Zemeckis, estreou no Brasil em 26 de janeiro de 2001 (Cinema em Cena). O filme conta a história de Chuck Noland, interpretado por Tom Hanks. Chuck é um engenheiro de operações da empresa Federal Express (FedEX). Sua vida é ditada por horários e seu trabalho é realizado em função do tempo (Náufrago, 2000).

Em meio às festas de natal, Chuck embarca num avião da empresa, lotado de pacotes a serem entregues. A viagem acaba mal sucedida, acontecendo um acidente que leva Chuck a uma ilha deserta. Após todas as buscas, sua família e amigos acreditam que ele morreu e agora, de fato, Chuck está sozinho na luta pela sobrevivência.

Os primeiros momentos do personagem na ilha são dramáticos numa busca por comida, água e abrigo. Os pacotes da FedEX que estavam no avião acabam chegando à praia e ele começa a abri-los, guardando somente um, que promete a si mesmo que será entregue. Num dos pacotes, Chuck descobre uma bola de vôlei, que se torna sua companhia, juntamente com uma foto da namorada. Ele dá à bola o nome de Wilson, a marca do produto, e nela desenha um rosto.

A história se desenvolve e Chuck consegue voltar para casa, com seus próprios esforços e à custa da perda de seu único "amigo" durante quatro anos: Wilson. Mas ao voltar, as coisas estão diferentes,. Kelly se casou e possui uma família e ele está mudado, o que implica num final diferente do esperado feliz hollywoodiano. As cenas finais mostram Chuck num carro, com um pacote da empresa para a qual trabalha. Ele deixa o pacote na porta de uma casa com uma mensagem de que aquele pacote lhe salvara a vida. Perdido na estrada, Chuck encontra uma mulher que lhe indica a direção certa. O filme termina com o personagem de Tom Hanks no meio da estrada (IMDB).

Náufrago teve um orçamento de noventa milhões de dólares (E-Pipoca). Mesmo o filme tendo dividido a opinião dos críticos, a resposta do público foi positiva: a obra arrecadou no total cerca de 428 milhões de dólares (FILMECAM). Isabela Boscov explica o sucesso: "há dois motivos para esse desempenho: a produção tem um roteiro muito engenhoso e a atuação de Hanks é simplesmente mag- 
nífica" (BOSCOV, 2009). Vale lembrar que, apesar de muitas pessoas criticarem a presença da FedEx no filme, o diretor já garantiu em diversas entrevistas que a empresa não pagou nada para ter sua marca inserida (IMDB).

O filme recebeu 24 indicações de prêmios, entre elas duas ao Oscar. Ganhou onze prêmios, sendo o de maior representatividade o Globo de Ouro (2001), na categoria de melhor ator, para Tom Hanks.

\subsection{0 enredo por trás das imagens}

A história que Robert Zemeckis se propõe a contar em Náufrago (2000) é bem simples: um homem que vai parar numa ilha deserta e tem de lutar pra sobreviver. Mas essa simplicidade não deve ser vista como uma desvalorização, pois, por meio de uma história simples, o filme propõe uma reflexão do que a sociedade moderna considera importante.

Chuck Noland, personagem de Tom Hanks, é um homem contemporâneo em todos os detalhes. Ele tem um trabalho estressante, uma vida corrida, uma namorada esperando por ele, celular, uma agenda lotada e uma dor de dente que incomoda muito. O tempo é seu maior amigo e pior inimigo.

Quando acontece o acidente, Chuck embarca numa jornada do que é ser humano: ele tem de se adaptar ao seu novo cenário. Tudo que era importante na "civilização" do protagonista - celular, relógio, pager - não pode ajudá-lo na ilha. Segundo o roteirista, ele precisa aprender a sobreviver primeiro fisicamente e, depois, emocionalmente (Náufrago, 2000). O espectador assiste a um homem que não é capaz de abrir um coco. E surge aí uma pergunta: até que ponto o ser humano é autossuficiente hoje? O protagonista é a representação de uma sociedade moderna, controlada pelo tempo e completamente dependente da tecnologia, até mesmo para abrir um coco. 


\section{Figura 1}

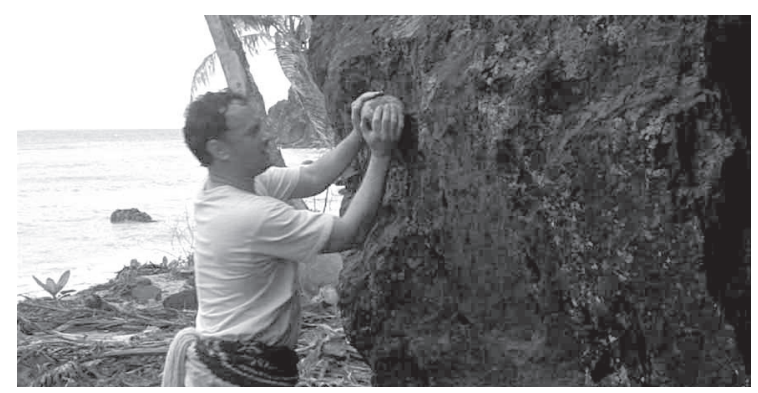

Fonte: Náufrago (2000, 00:40:49)

Uma das cenas mais importantes do filme é quando Chuck consegue acender uma fogueira. Isso representa a evolução do personagem enquanto humano, pois aprender a manipular o fogo em seu favor foi uma das maiores conquistas da humanidade.

\section{Figura 2}

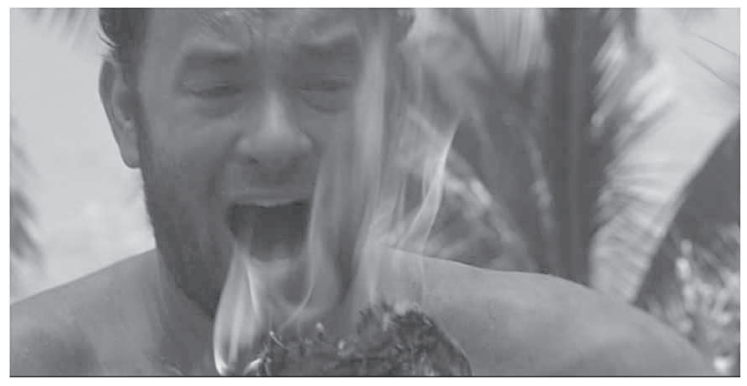

Fonte: Náufrago (2000, 01:12:14).

Como ser humano, Chuck também precisa do outro. A necessidade de conversar e manter sua sanidade faz com que ele dê a um objeto inanimado - uma bola de vôlei - características humanas e assim o eleja como companheiro. Nasce um personagem extremamente importante para o filme: Wilson. 


\subsection{Wilson}

\subsubsection{A construção do personagem}

Wilson é uma bola, um objeto completamente inanimado. O que, então, faria dele um personagem e não um objeto de cena? Wilson se desenvolve durante o filme. Ele se torna um personagem por meio do protagonista e da interação dos dois no decorrer da história. E mais do que isso, torna-se um personagem singular. Pode-se classificá-lo como um coadjuvante, não humano. Mas, diferente do objeto que ganha vida, como em Toy Story (1995) de Jonh Lasseter, ou em O brinquedo assassino (1988) de Tom Holland, Wilson permanece inanimado até o fim do filme. A proposta deste tópico, e deste trabalho como um todo, é analisar as características de construção desse personagem secundário.

Wilson se classifica como um personagem redondo. Essa classificação se dá devido à sua profundidade.

A personagem redonda é mais complexa, evolui durante a narrativa, possui atitudes imprevisíveis [...] O personagem redondo geralmente muda no decorrer da história (SANTOS; COSTA, 2008, p.35).

Wilson evolui durante o filme, e faz isso num sentido muito complexo, pois ele passa de um objeto qualquer, um objeto de cena para um personagem. Na imagem abaixo, vê-se Wilson na cena, mas ele ainda não existe como personagem e sim como objeto.

\section{Figura 3}

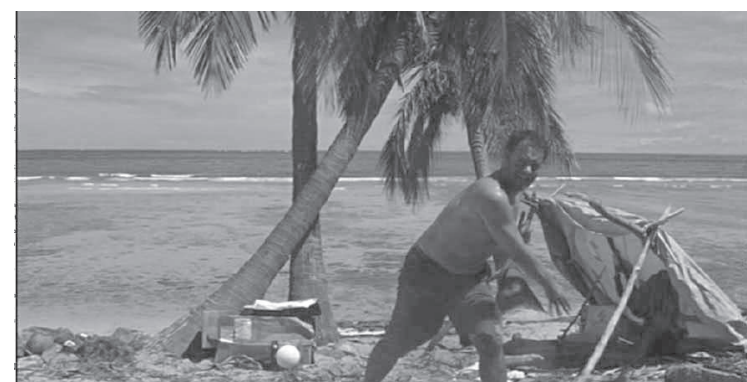

Fonte: Náufrago (2000, 01:07:51) 
A evolução de Wilson acontece na seguinte trajetória: primeiro ele é um pacote achado na praia, uma bola de vôlei. Quando Chuck desenha o rosto em Wilson, ele passa a ser alguém, mas ainda um estranho. A primeira fala de Chuck com a bola expressa bem isso: "Por acaso você não teria fósforos, teria?" (Náufrago, 2000, 01:10:48). Com o passar do tempo, Chuck se torna amigo de Wilson. Nos extras do DVD Náufrago, Tom Hanks diz que a amizade entre Wilson e Chuck se desenvolve como uma amizade comum, sem que o protagonista force um relacionamento. (Náufrago, 2000, 06:21). O relacionamento deles é tão real que chega a passar por crises. Tom Hanks colocou isso dizendo que achava que nenhum relacionamento aguentaria tanto tempo sem outras pessoas, portanto, depois de quatro anos, eles já não se davam tão bem. Mas quando aparece uma novidade, a possibilidade de salvação, então havia sobre o que falar, e o casamento dura um pouco mais (Náufrago, 2000, 00:00:52).

O fator mais peculiar de Wilson é realmente o fato de ele ser um objeto completamente inanimado nas imagens, mas que deve incentivar o espectador a imaginá-lo como alguém real. Ou seja, o espectador não vê Wilson falando, mas ele imagina as falas dele. O diretor do filme tomou cuidado ao transmitir isso nas cenas. A câmera subjetiva, usada com frequência em filmes para que o público veja por meio da percepção do personagem, não é utilizada de fato com Wilson. Não há nenhuma cena do filme em que se pode afirmar que o espectador vê através de Wilson, porque dessa forma, a bola ganharia vida nas telas, pois ela passaria a enxergar. Mas, sabiamente, o diretor sugere essa câmera, como se o público pudesse ver através de Wilson. Em algumas cenas de "diálogo" entre Chuck e Wilson, a câmera incita a ilusão de Wilson estar olhando para o personagem principal. Essa ilusão se dá pelo fato de Wilson não aparecer na cena da conversa. Porém, pode-se perceber pela distância do personagem principal para a bola ou pelo ângulo da câmera que, de fato, não se vê pelos olhos de Wilson. As imagens abaixo ilustram essa sugestão. Na figura 10, Wilson está em cena, de costas para a câmera, e Chuck olha para ele. 


\section{Figura 4}

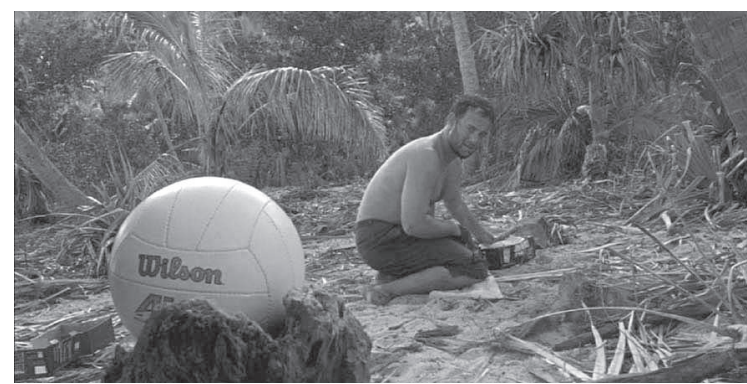

Fonte: Náufrago (2000, 01:10: 08).

Alguns segundos depois, Chuck olha novamente para Wilson. Mas a bola já não está presente na cena, fazendo com que ele olhe, aparentemente, para quem está vendo o filme.

\section{Figura 5}

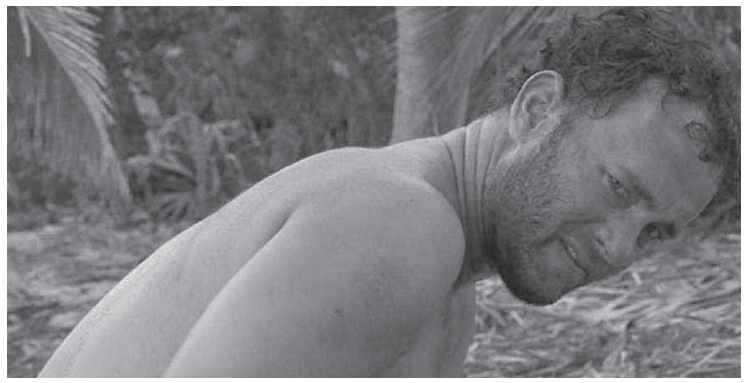

Fonte: Náufrago (2000, 01:10:28).

É possível perceber que ele não olha diretamente para a câmera, sendo assim não se pode afirmar que é uma câmera subjetiva, mas sim uma suave sugestão.

A câmera "quase" subjetiva tem a função de criar uma empatia do público com Wilson. Esse recurso ajuda o espectador a assimilar a bola como um personagem e, mais do que isso, colabora para que o público viva o personagem secundário, pois quando Chuck olha para a bola, na verdade ele olha para o público, quando faz perguntas à bola, é na mente do espectador que surgem as respostas.

No cinema, a câmera carrega o espectador para dentro do filme. Vemos tudo como se fosse do interior, e estamos rodeados pelos personagens. Estes não precisam nos contar 
o que sentem, uma vez que nós vemos o que eles vêem e da forma em que vêem. [...] Nosso olho, e com ele nossa consciência, identifica-se com os personagens no filme (XAVIER, 1991, p. 85).

Analisando a construção do personagem, vê-se que Wilson não possui alguns aspectos bem definidos, tais como nacionalidade, profissão e paradoxos.

Personagens não surgem do nada. Eles são um produto do meio em que existem [...] Os contextos que mais influenciam as personagens são a cultura, o período histórico, o local em que vivem e sua profissão (SEGER, 2006, p. 17).

As personagens ficam mais interessantes se forem compostas de características variadas, se combinaram elementos conflitantes e paradoxais (TOURNEY apud SEGER, 2006, p. 45).

Sua descrição física é algo óbvio; ele é uma bola e suas emoções, atitudes e detalhes, que lhe conferem exclusividade, existem a partir do protagonista e do espectador. Wilson não demonstra emoção, quem sente por ele é o protagonista e o espectador. Um exemplo disso pode ser visto na cena em que Chuck chuta Wilson para fora da caverna.

\section{Figura 6}

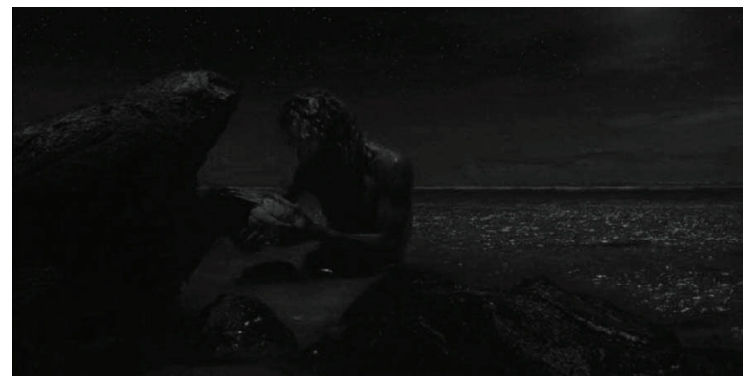

Fonte: Náufrago (2000, 01:30:53).

Quando Chuck se dá conta do que fez, sai à procura de Wilson e, no encontro, a emoção fica por conta do protagonista. Os detalhes de Wilson e sua caracterização vêm também do personagem principal, pois é ele quem constrói o personagem, dando-lhe um rosto. $\mathrm{O}$ rosto é o fator mais marcante da construção de Wilson, é seu atributo principal. Os atributos fazem parte de um tópico posterior. 


\subsubsection{O personagem secundário}

Construir um personagem coadjuvante requer cuidado assim como a construção de um protagonista.

Muitos dos princípios usados na criação dos personagens principais também se aplicam às personagens coadjuvantes. Elas também precisam ser consistentes, possuir atitudes, valores e emoções, além de apresentar em geral algumas características paradoxais (SEGER, 2006, p. 133).

Wilson é um personagem secundário, e as características de um coadjuvante - função, contraste com os demais personagens, detalhes - estão bem definidas nesse personagem. Ele tem uma função clara: reforçar a solidão do protagonista. Chuck está tão sozinho que elabora um sujeito numa bola e essa bola é sua única companhia pelo tempo em que está na ilha. Wilson tem essa função primordial e ele é extremamente necessário para a história. Steve Watts, especialista em tecnologia primitiva, afirma que Wilson é indispensável à sobrevivência de Chuck (Náufrago, 2000, 00:00:53). Uma função secundária de Wilson é ajudar a comunicar o enredo. O conflito da história é vivido por Chuck Noland, mas Wilson ajuda a contar esse enredo. Se o enredo propõe uma reflexão a respeito de como a sociedade leva sua vida no século XXI, Wilson é a representação do outro,e, no contexto do filme, ele é a necessidade que o ser humano possui de companhia.

É interessante que os personagens secundários apresentem algum contraste, ou com o protagonista ou com outro personagem secundário. Com relação à personalidade, os contrastes de Wilson são relativos, pois eles dependem da interpretação do espectador. Isso acontece porque não há nada que mostre a personalidade de Wilson, de uma maneira definitiva. A personalidade dele existe, mas ela é variável. Tom Hanks afirma que "Wilson tem uma personalidade tão bem definida quanto a minha ou de qualquer um de nós" (Náufrago, 2000, 00:01:03), mas podese interpretar que essa personalidade tão bem definida da qual o ator fala é real somente para ele. Um exemplo claro dessa mutação da personalidade de Wilson pode ser vista quando o roteirista diz que no momento em que escreveu Wilson, ele o imaginava como um sujeito bonzinho, calmo e compreensivo. Mas, para Tom Hanks, ele era alguém muito mais engraçado, que muitas vezes provocava o amigo (Náufrago, 2000, 00:07:20). Sendo assim, a personalidade de Wilson também pode variar a partir do que o espectador pensa dele, ou até mesmo da parte de sua perso- 
nalidade que o espectador colocará no personagem. A partir dessa personalidade, os contrastes sairão. Se o espectador encara Wilson como um pessimista, há certo momento do filme em que ele pode ser um contraste com Chuck: quando ele diz a Wilson que eles têm tempo para que o plano dê certo. A entonação do protagonista sugere que Wilson diz "não temos tempo".

\section{Figura 7}

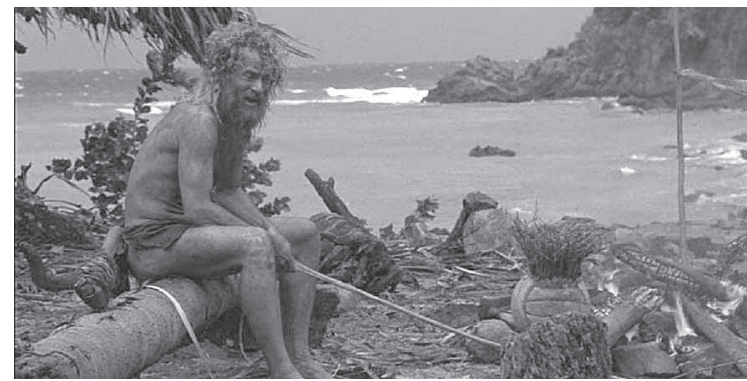

(Náufrago, 2000, 01:27:10).

Se ele é otimista, o contraste pode estar na cena em que Chuck precisa do fogo e já não aguenta mais tentar fazer uma fogueira. Mas Wilson está ali, "olhando" para ele numa posição de quem pode dizer: "vamos, você vai conseguir".

\section{Figura 8}

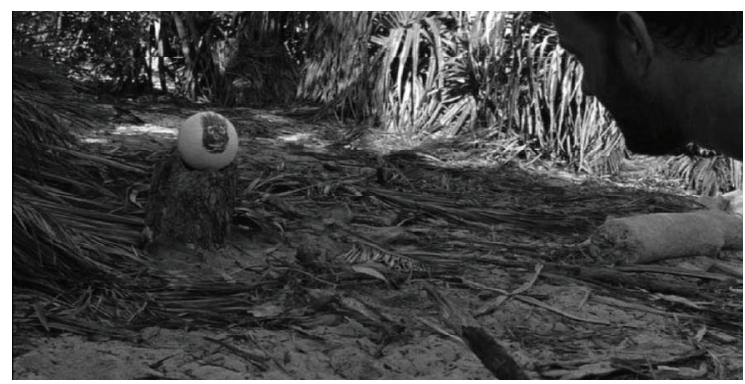

Fonte: Náufrago (2000, 01:10:10).

No que diz respeito ao elemento físico, Wilson apresenta uma espécie de sorriso. Sorriso esse que Tom Hanks considerou como enigmático, travesso (Náufrago, 2000). Esse aspecto do sorriso do coadjuvante contrasta com a situação vivida pelo protagonista. Chuck está,em quase todas as cenas, sério, triste, deprimido. E Wilson está sempre sorrindo. 


\section{Figura 9}

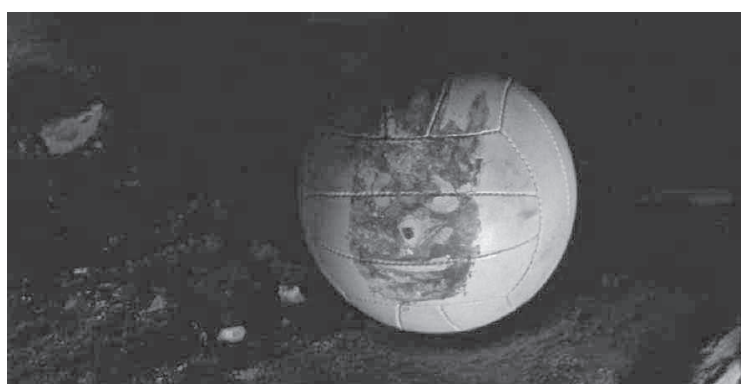

Fonte: Náufrago (2000, 01:15:23).

\subsubsection{O personagem não humano}

Personagens não humanos aparecem com muita frequência. Algumas vezes como protagonistas, outras como coadjuvantes. Essa categoria engloba animais e objetos, imaginários ou fantásticos. Para dar vida a esses personagens, os autores utilizam alguns recursos, entre eles dar à criatura não humana características humanas. Para que a criatura não humana se torne um personagem interessante e bem planejado, Linda Seger sugere alguns passos: escolher cuidadosamente um ou dois atributos que começarão a definir a identidade da personagem; enfatizar as associações que a própria audiência faz com a personagem, de forma a expandir ainda mais sua identidade; criar um sólido contexto que contribua para dar profundidade à personagem (SEGER, 2006, p. 193).

Wilson é um personagem não humano, mas como personagem ele exibe características humanas. Seguindo os passos sugeridos por Linda Seger para a criação de um personagem não humano, identificam-se em Wilson dois atributos principais: o rosto e a lealdade a Chuck. Quando Wilson ganha um rosto, ele perde a identidade de objeto e ganha o aspecto de sujeito. Chuck Noland não conversa com Wilson visto que ele é só uma bola, ele só conversa com Wilson quando vira um sujeito. Esse aspecto de Wilson permite ao personagem de Tom Hanks e ao público enxergá-lo como alguém e não como um objeto. Com relação à lealdade, o coadjuvante permanece com Chuck até sua morte. A lealdade existe também porque sem Chuck, Wilson não existe, ele depende do protagonista para existir, ele é uma parte dele. Tanto é assim que seu aspecto humano mais forte vem do sangue de Chuck. O roteirista diz que isso é uma forma de demonstrar que Wilson vem 
de Chuck (Náufrago, 2000). Esses atributos são imutáveis. Wilson sempre tem um rosto e sempre está ali por causa do protagonista.

Wilson está associado à amizade, ao relacionamento humano e à sanidade mental. A bola é aceita como personagem porque o público associa a ela o medo da completa solidão e da loucura. O contexto do personagem no filme é muito claro: ele é fruto da solidão de Chuck. Wilson surge quando o protagonista mais precisa dele. Sua primeira aparição é quando Chuck precisa fazer fogo e não consegue. Os gritos do protagonista ao machucar a mão revelam que ele já está entrando em desespero.

\section{Figura 10}

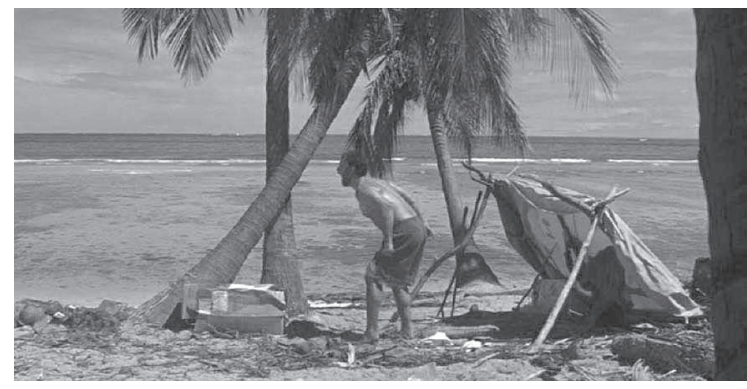

Fonte: Náufrago (2000, 01:07:59).

É nesse momento que Wilson "aparece”. Analisando um contexto geral, Wilson está imerso num panorama no qual os relacionamentos humanos se dão com objetos, e como exemplo mais claro tem-se o computador. As pessoas se relacionam com uma máquina, na "ilusão" de estarem se relacionando com uma pessoa.

Esses passos fortalecem Wilson como personagem. Os diálogos do protagonista combinado com todas essas características de construção de personagens elegem Wilson como um coadjuvante essencial ao enredo. 


\title{
2.4 Product Placement
}

A relação entre publicidade e cinema é de proximidade. É preciso entender que o cinema hollywoodiano é uma indústria (PARAIRE, 1994, p.7) e, por isso, existe uma série de táticas de marketing que envolve um filme.

Product placement é uma nomenclatura nova para uma técnica já usada há muito tempo. Joanne Weintraub cita em seu artigo que, segundo Jay Newell, da Universidade do Estado de Iowa, em Ames, os irmãos Lumiére, em 1890, já tinham um associado que trabalhava na área da publicidade para a empresa Lerver Bros, hoje, mundialmente conhecida como Unilever. Ele afirma ainda que não é por acidente que a Sunlight Soap pode ser amplamente vista em várias distribuições dos Lumiére (WEINTRAUB, 2005).

Segundo Patrícia Burrowes, em sua definição, product placement refere-se, "na linguagem do marketing, a colocação tática de produtos em filmes, programas de TV, jogos de computador e mesmo em romances e canções" (BURROWES, 2008), ou seja, estrategicamente a empresa paga para inserir seus produtos ou marca no filme. Essa tática ainda chamada por muitos de merchandising, merchandising editorial ou ainda TIE - IN funciona para a propaganda que possui o intuito de levar o consumidor à compra; e também para o filme, à medida que insere elementos do cotidiano do espectador no enredo, trazendo assim mais verossimilhança à narrativa. Michael J. Etzel, Bruce J. Walker e Willian J. Stanton (2001, p. 508). falam sobre o assunto.

\begin{abstract}
Você já deve ter notado a colocação de produtos no filme de James Bond, Goldeneye (computadores IBM, BMW, Perrier e Omega), ou nas séries de TV Baywatch (bronzeadores Hawaiian Tropic) e Seinfeld (TV Guide, Snapple, doces Mars, Junior Mints). Entretanto, se você for como a maioria dos telespectadores, esses produtos apenas se somaram ao realismo da apresentação, e aí está a força da colocação de produtos. Ela relaciona o produto com os personagens do programa, de forma não comercial, criando uma associação positiva para a audiência.
\end{abstract}

\subsubsection{O product placement em Náufrago}

Náufrago foi muito criticado por ter a presença tão marcante das marcas FedEx e Wilson. O editor do site Cinema em cena avaliou “[...] No início, o filme peca pelo exagero, pela exaltação da FedEx em cena [...] “ (RUSSO, 2009). 
O filme parecia uma grande propaganda das empresas. Mas o fato é que o diretor já garantiu que as empresas não pagaram para inserir suas marcas no enredo. Sendo assim, não se pode afirmar que existe um product placement no filme, pois as empresas não pagaram para aparecer nele. Entretanto, serviu como uma propaganda às duas empresas.

No caso da FedEX, o fato de inseri-la traz para o enredo uma veracidade maior, pois coloca uma empresa real numa história fictícia. A empresa trabalha com prazos pré-determinados e garantia de entrega, e o fato de o protagonista trabalhar lá corrobora para a construção, pois ,um dos aspectos importantes de um personagem é a sua profissão e sua relação com o cotidiano.

Essa propaganda não paga trouxe muitos benefícios à FedEX, entre eles a divulgação do nome da empresa em diversos países do mundo, nos quais o filme foi exibido. A eficiência do serviço prestado também foi bem divulgada, pois não é à toa que o protagonista entrega, no fim do filme, um dos pacotes que foram parar na ilha, o único que ele não abriu. A empresa ganhou um status de propósito de vida para o personagem Chuck, pois ele guarda o pacote na intenção de entregá-lo. Os pacotes na ilha tornaram-se um conflito entre responsabilidade e sobrevivência, vivido pelo protagonista: mesmo perdido na ilha, ele reluta em abrir as correspondências que não lhe pertencem e que fazem parte de seu trabalho de excelência. $O$ que está por trás disso é a mensagem da garantia da entrega da FedEx. Mesmo em situações difíceis, a FedEx entrega sua encomenda.

\section{Figura 11}

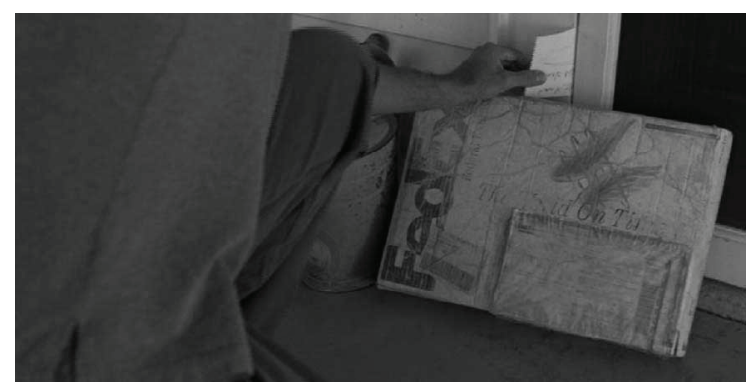

Fonte: Náufrago (2000, 02:14:00).

Analisando Wilson, pode-se perceber claramente a intenção de inserir a marca. Basta ver na figura 17, em uma das tomadas do filme, a marca fica em primeiro plano. 


\section{Figura 12}

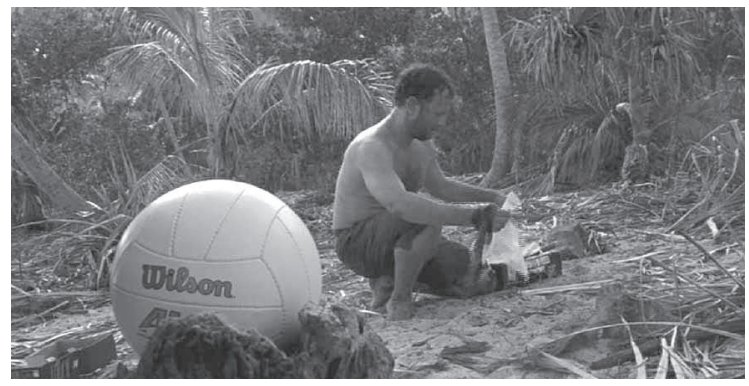

Fonte: Náufrago (2000, 01:10:02)

É evidente que a marca Wilson foi bastante acertada para esse personagem, pois a coincidência entre o nome da marca e um nome pessoal ajuda a colocar a bola na categoria de integrante do filme, como sujeito, e auxilia a identificação com o espectador. Talvez outra marca não se encaixasse tão bem nesse aspecto. Uma bola das marcas Adidas ou Nike, apesar de possuírem nomes fortes, não teriam o mesmo apelo do nome que Wilson tem.

O importante a ser analisado aqui é a proposta que Náufrago (2000) apresentou à publicidade, sobretudo com relação a Wilson. A construção leva o consumidor a uma identificação com o personagem, que é uma marca. Foi um product placement? Não, tradicionalmente não, mas foi uma ideia tão bem elaborada, que pode ser utilizada na publicidade. O enredo descaracterizou Wilson como produto e o caracterizou como um personagem. Dessa maneira, a barreira que o consumidor/espectador tem contra propagandas foi derrubada para a aceitação desse personagem. Mas o fato de não identificá-lo como produto não elimina a marca, pelo contrário, o sentimento que o espectador emprega ao personagem Wilson poderá ser lembrado quando ele vir a marca em uma loja. E talvez ele escolha a bola, e por sua vez a marca Wilson como companheira.

\section{Considerações finais}

Robert Zemeckis conseguiu fazer da história simples de Náufrago um poço de questões a serem analisadas. O filme trouxe uma reflexão em seu tema e personagens sólidos. De uma maneira criativa e bem feita, o monólogo de Tom Hanks torna-se um diálogo. 
A bola de vôlei se tornou um personagem que abrange vários dos diversos aspectos da construção de personagem. É importante entender que Wilson não está no filme sem um motivo, mas ao contrário, sua presença é indispensável ao enredo.

Sendo Wilson um objeto completamente inanimado, Robert Zemeckis encarou um desafio ao elegê-lo como coadjuvante, tendo em vista que ele não poderia demonstrar emoções, atitudes ou ter diálogos. Para o sucesso desse personagem, a atuação do protagonista teria de ser excelente, pois Wilson se desenvolve a partir da interação dos dois. E a esse respeito, Tom Hanks não deixou a desejar, prova disso foi a vitória do Globo de Ouro de Melhor Ator (2001).

Mesmo contendo esse diferencial dos personagens e uma história que propõe uma reflexão, Robert Zemeckis não abandonou seu "lado hollywoodiano". Ele empregou no filme os efeitos especiais de que tanto gosta, e características de blockbusters, como o batido final feliz. É verdade que o final feliz não é o mais convencional, afinal Chuck não ficou com Kelly. Mas a sugestão do happy end está lá, quando o protagonista encontra uma bonita garota na estrada, já na última cena.

As marcas inseridas no filme também foram bem trabalhadas, ficando coerentes com o enredo. Essa inserção mostra o quanto a publicidade ainda tem espaço de entrada na mídia e caminhos a percorrer. Mas, mais do que isso, ela apresenta um modelo de product placement diferente, pois, em Wilson, ela descaracterizou o produto para transformá-lo em personagem. E essa diferenciação na técnica pode ser uma chave de sucesso, ao transformar a marca e o produto em mais do que uma marca ou um produto e aproveitando do elo personagem-espectador para criar um elo produto-consumidor.

O filme tem ainda muitas vertentes de análise. O enredo abre as portas para uma discussão a respeito da sociedade moderna, do tempo e das prioridades das pessoas. Ao personagem Wilson, cabem análises mais profundas no aspecto de ele ser uma extensão do protagonista, ser a representação do outro e a materialização da sanidade do protagonista. O homem vive em sociedade e Wilson é a sociedade de Chuck: ele é o seu universo na ilha. Embora minimamente abordadas aqui, essas outras vertentes de análise podem ser, futuramente, temas de um trabalho mais extenso. 


\section{Wilson: an analysis of the supporting character in the movie Castaway}

\section{Abstract}

The characteres are the main means of identification with the movie. To have a good character is necessary to think about his construction. This constructions involves several aspects: context, essence, paradoxes, physicals characteristics. This article's main objective is to make an analysis about the construction of a supporting character Wilson in Castaway (2000), from Robert Zemeckis. Wilson is a volley ball, a completely inanimate object, which appropriates several aspects of a secondary character not human. The volleyball still has another point of analysis, discussed in this work in a secondary way: the advertising involved in it. The product placement, strategic isertion technique of brands in movies, music and shows of television, presents - a non traditional way - in Castaway (2000), more precisely in the brands Federal Express (FedEX) and Wilson, and in the latter brings a diferentiated model of advertising.

Keywords: Cinema. Character. Supporting Character. Product Placement.

\section{Referências}

ANTUNES, Nathalia Alencar. Wilson: uma análise do coadjuvante no filme Náufrago. Brasília, 2008. 61 p. Monografia (Graduação)- Comunicação Social com habilitação em Publicidade e Propaganda, Centro Universitário de Brasília, Brasília, 2008.

BOSCOV, Isabela. Não é mole ser Tom Hanks. Veja online, São Paulo, 2009. Disponível em: <http://veja.abril.com.br/240101/p_120.html>. Acesso em: 6 maio 2009.

BURROWES, Patrícia. Cinema entretenimento e consumo: uma história de amor. Revista FAMECOS, Porto Alegre, n. 35, abr. 2008. Quadrimestral. Disponível em: <http://www.revistas.univerciencia.org/index.php/famecos/ article/ view/5365/4884.htm>. Acesso em: 15 abr. 2009.

ETZEL, Michael J.; WALKER, Bruce J.; STANTON, William J. Marketing. São Paulo: Makron Books, 2001. 
NÁUFRAGO. Produção de Therr Lgged Cat Prods, Mark Rance, Albert Ihde. Los Angeles: DreamWorks Picture, Twentieth Century FOX, 2000. 2 DVD's (143 min), NTSC, son., color.

PARAIRE, Philippe. O cinema de Hollywood. São Paulo: M. Fontes, 1994.

RUSSO, Francisco. Comentários. Adoro cinema. Disponível em: <http://www. adorocinema.com/filmes/naufrago/critica10.html>. Acesso em: 25 maio 2009.

SANTOS, Robson Souza dos; COSTA, Felipe da. Imagens do Brasil: o cinema brasileiro e a construção da identidade nacional. Revista do NP de comunicação audiovisual da INTERCOM, São Paulo, v.1, n. 2, p. 35-58 ago./dez. 2008. Disponível em: <http://www.revcom2.portcom.intercom.org.br/index.php/NAU/article/ view/5362/4912.htm>. Acesso em: 03 abr. 2009.

SEGER, Linda. Como criar personagens inesquecíveis. São Paulo: Bossa Nova, 2006.

TURNER, Graeme. Cinema como prática social. São Paulo: Summus, 1994.

WEINTRAUB, Joanne. Product Placement is a super tradicion in Hollywood. Entertainment: TV and radio. Milwaukee, mar. 2005. Disponível em: <http:// www3.jsOnline.com/story/index.aspx?id=305598.htm>. Acesso em: 17 abr. 2009.

XAVIER, Ismail. A experiência do cinema. 2. ed. Rio de Janeiro: Graal, 1983. 
